\title{
Forsking med brukarar kan gi forbetra kvalitet på kols-tenester
}

Eit prosjekt der brukarar og tenesteytarar var medforskarar , identifiserte sårbare område, unytta ressursar og uimplementerte retningsliner i kols-omsor ga.

\section{Forfattarar}

\section{Anne-Grethe Halding}

Sjukepleiar og førsteamanuensis

Institutt for helse- og omsorgsvitskap, Høgskulen på Vestlandet

Evy Irene Aarsheim

Ergoterapeut

Flora kommune

Aud Jenny Jensen

Brukar

Sissel Stavøstrand

Brukar

Ellen Karine Grov

Professor II

Institutt for helse- og omsorgsvitskap, Høgskulen på Vestlandet

\section{Nøkkelord}

\begin{tabular}{l|l|l|l|l} 
Brukermedvirkning Helsetjeneste Lungesykdom Rehabilitering & kols
\end{tabular}

Sykepleien 2018 106(73457)(e-73457)

DOI: https://doi.org/10.4220/Sykepleiens.2018.73457 
I Noreg er samarbeidsforsking lite nytta i helseforsking innan somatiske helsetenester. Vi har gjennomført eit samarbeidsforskingsprosjekt på kols-feltet, der vi har hatt sterk brukarinvolvering. Ein slik design synes godt egna for kunnskapsutvikling innan oppfølgingstenester. I studien fann vi òg at nasjonale retningsliner slett ikkje var tilstrekkeleg implementerte.

Brukarar av helsetenester eller pasientar (heretter kalla brukarar) vert i aukande grad involverte i fagutvikling og forsking, og eit formalisert samarbeid med «dei det gjeld», er no eit krav i søknader om forskingsmidlar (1, 2). Brukarmedverknad kan gi nye perspektiv og problemstillingar som er viktige bidrag til kunnskapsbaserte helsetenester, men det krev tilrettelegging og sterk involvering dersom medverknaden skal vere reell $(3,4)$.

I Noreg er det mest i helseforsking innanfor psykiatriog rusfeltet ein har nytta brukarinvolvering $(5,6)$, og i mindre grad i somatikken. I denne artikkelen formidlar vi erfaringar og nokre resultat frå samarbeidsforsking på feltet kronisk obstruktiv lungesjukdom (kols).

Forfattarane har tidlegare arbeidd med oppfølgingstenester for personar som lever med kols, og vi har sett verdien av å nytte brukarkunnskap når ein utviklar slike helsetenester. Tilboda om oppfølgingstenester på kols-feltet er mangelfulle, og langtidsutbytet av eksisterande tenester er usikkert (710). Vi hadde òg erfart at eksisterande tilbod vart for lite nytta.

Samhandlingsreforma (11) har som mål å utvikle meir pasientsentrerte tenester, å betre samhandlinga mellom tenester og mellom tenestenivå, og å gi kommunane meir ansvar for oppfølginga av langvarig sjuke. På kols-feltet kom det ei ny nasjonal fagleg retningsline i 2012 (10). Det er enno ikkje gjort nasjonal evaluering av desse tenestetilboda etter samhandlingsreforma og dei nye kols-retningslinene. 
Spørsmåla vi stilte oss, var følgande: Korleis er situasjonen for denne gruppa etter samhandlingsreforma og nye nasjonale retningsliner? Korleis kan vi bidra til kvalitetsutvikling av tenestene? Dette prosjektet vart planlagt og gjennomført i samarbeid mellom brukarar, tenesteytarar og forskarar.

\section{Kva er kols?}

Kols er den fjerde hyppigaste dødsårsaka i verda, og sjukdommen representerer ei stor utfordring for samfunnet og dei som lever med han. Kols progredierer, gir degenerering av respirasjonssystemet, og forverringsepisodar og komorbiditet som hjartesjukdom, vekttap, fatigue, smerter, depresjon og angst reduserer livskvaliteten til den enkelte. Typiske symptom er dyspnoe, hoste, auka slimproduksjon og nedsett funksjonsnivå (7).

\section{三 «Kols er den fjerde hyppigaste dødsårsaka i verda.»}

Kols kan ikkje lækjast, men tilpassa farmakoterapi og eigenomsorg, rehabilitering og pasientopplæring, i tillegg til oppfølging, kan redusere symptom, forverringsepisodar og progresjon, og betre livskvaliteten til den enkelte (7).

\section{Ulike tilbod}

Det er utarbeidd nasjonale og internasjonale retningsliner for behandling og oppfølging (7-10). Dei nasjonale retningslinene (10, s. 61) har spesifikke tilrådingar for oppfølging i stabile fasar, der hovudinnhaldet er

- oppfølging hjå allmennlege ein til to gonger årleg og innan fire veker etter sjukehusinnlegging

- røykeslutthjelp når det er aktuelt

- tilvising til fysioterapi ved moderat og alvorleg kols

- tilvising til ergoterapi dersom pasienten har vanskar med å greie daglege aktivitetar 
- tidleg opplæring og motivering til livsstilsendring

- tilbod om rehabilitering etter sjukehusinnlegging på grunn av forverring

- rehabiliteringstilbod i alle kommunar

- spesialiserte rehabiliteringstilbod ved alle helseføretak etter ei tverrfagleg vurdering

I Noreg er rehabilitering, pasientopplæring og oppfølging ulikt organisert i dei ulike kommunane og helseføretaka: lokalmedisinske senter, kolsmeistringskurs i kommunar, lærings- og meistringskurs (LMS) i spesialisthelsetenesta, rehabilitering i helseføretak og i regi av pasientorganisasjonar, og kontrollar i helseføretak eller hjå fastlege.

\section{Samarbeidsforsking}

Kols-retningslinene tilrår òg opplæring til eigenomsorg (10). Sjukdomsspesifikk og samarbeidsbasert eigenomsorg er ein viktig del av oppfølginga, og då må brukaren ha hovudrolla i samarbeid med helsevesenet $(12,13)$. Brukarerfaringar er difor ein sentral del av kunnskapsgrunnlaget for oppfølginga.

Forskingsdesign som inkluderer brukarar, kan kallast samarbeidsforsking eller medforsking, og brukarane kan kallast medforskarar $(5,6)$. Samarbeidsforsking skal inkludere sentrale aktørar i den praksisen ein studerer. Hovudprinsippet er at dei som bruker tenestene, og i nokre tilfelle tenesteytarane, skal delta likeverdig. Ved sterk involvering deltek medforskarane i alle fasar av eit prosjekt. Metodologien er enno lite utvikla $(4,14,15)$.

\section{Planlegging av prosjektet}


Vi etablerte ei prosjektgruppe med deltakarar frå nærområdet: fire brukarar, to tenesteytarar og tre forskarar. Brukarane vart rekrutterte frå ei pasientforeining, frå ei brukarstyrt nettverksgruppe og på ein fagdag, og tenesteytarane var ein sjukepleiar og ein ergoterapeut tilsette i oppfølgingstenesta i spesialist- og primærhelsetenesta. Både tenestebrukarane og tenesteytarane blir i denne artikkelen kalla medforskarar.

Forskarane hadde erfaring frå samarbeids- og kolsforsking, og fleire i gruppa kjende kvarandre frå tidlegare fagleg samarbeid. Høgskulen i Sogn og Fjordane og Extrastiftelsen via Landsforeningen for hjerte- og lungesyke har finansiert prosjektet, og Flora kommune og Helse Førde har late tenesteytarane delta i prosjektet i arbeidstida.

Gjennom gruppesamarbeid utvikla vi eit forprosjekt og eit hovudprosjekt. Ein viktig del av forprosjektet var medforskarkurset på 24 timar, inspirert av ein medforskarskule arrangert av Regionalt forskingsnettverk for stemningslidingar, Moodnet (16). Kurset inneheldt grunnleggjande opplæring om kvalitetsforbetring og forsking, gjennomført med førelesingar, diskusjonar og øvingar, og vi fekk hjelp frå fagfolk med spesialkompetanse på områda og brukarar med erfaring frå samarbeidsforsking.

\section{Hovudprosjektet}

Hovudprosjektet vart utvikla parallelt med kurset, og innhaldet kunne difor tilpassast prosjektet. Vi prøvde å oppnå likeverdig deltaking i alle delar av planlegginga og gjennomføringa: behovsutgreiing, mål og metodar i tråd med prinsipp for sterk brukarinvolvering (17). Arbeidet vart fordelt etter kompetanse, til dømes gjorde forskarane litteratursøk, skreiv søknader og underviste, og medforskarane bidrog med erfaringskunnskap og med prioriteringar ut frå personlege erfaringar og samarbeid med andre brukarar. 
Gjennom heile prosessen la vi vekt på praktisk tilrettelegging og godt samarbeidsklima, mellom anna ved å setje av god tid til diskusjonar, uformelle samtalar og jamlege prosessevalueringar. Forprosjektet vart evaluert med fokusgruppeintervju, og hovudinntrykket frå evalueringsstudien var at dette hadde vore «eit givande, men krevjande samarbeid for å betre tenestene» (4).

I samsvar med dei prioriteringane medforskarane ønskte, utvikla vi hovudprosjektet med to delstudiar:

1. Ein tverrsnittstudie med survey for å kartleggje behov, tilbod og bruk av oppfølgingstenester

2. Ein deskriptiv kvalitativ intervjustudie for å utdjupe sentrale funn i delstudie I

Prosjektet vart tilrådd av REK Vest (referansenummer 2013/1301) med løyve frå Personvernombodet i Helse Førde (referansenummer 2013/ 5651).

\section{Metode}

Populasjonen i kartleggingsstudien var personar registrerte med kols som hovud- eller bidiagnose i Helse Førdes elektroniske pasientjournalsystem. 400 personar vart inviterte til å delta. Vi sende invitasjon med informasjon, spørjeskjema og samtykkeformular i vanleg post, og seinare ei purring til dei som ikkje hadde svart. Brukarane hadde stand der dei informerte om studien og medverka til rekruttering. Data vart samla inn i 2013-2015.

Instrumenta i delstudie I var dei norske versjonane av kols-vurderingstest (CAT, GlaxoSmithKline 2009) (18), Patient Activation Measure (PAM 13, Insignia Health) (19), Social Provision Scale (SPS, 16 spørsmål, omsette til norsk) (20) og eit ad hocspørjeskjema som inkluderte sosiodemografiske variablar. 
Medforskarane var sterkt involverte i utviklinga av det siste skjemaet, og prosjektgruppa testa alle skjemaa ved å fylle dei ut sjølve. Forskarane gjorde statistiske analysar, og alle var med på å velje ut funn til publisering og utforming av publikasjon (21). Forskarane laga førsteutkast til tekst på norsk, og dette vart presentert og diskutert på prosjektmøte der brukarane kom med kommentarar og innspel. Artikkelen vart til sist omsett til engelsk.

Til delstudie II gjorde vi eit strategisk utval av deltakarar frå delstudie I som hadde sagt ja til intervju, og som hadde CAT-skår 21-29, tilsvarande høg symptombyrde på grunn av kols (19). Gruppa utvikla intervjuguiden i samarbeid på grunnlag av formålet med studien og eksisterande kunnskap, inkludert funn frå delstudie I.

Prosjektleiaren og ein av medforskarane gjennomførte kvart intervju saman, og gruppa gjennomførte ein kvalitativ innhaldsanalyse og utforma manus i fellesskap. Ein artikkel om denne studien er no publisert i eit vitskapleg tidsskrift (22).

\section{Nokre forskingsresultat}

Det overordna målet med prosjektet var å identifisere sårbare område og unytta ressursar i kols-omsorga, og å vurdere funna opp mot faglege og politiske føringar. 116 personar deltok i delstudie I, og gjennomsnittsalderen var 69 år. 86 prosent hadde kolssymptombyrde mindre enn «svært høg» (CATskår <30).

\section{三 «Berre 44 prosent hadde vore til fastlegekontroll, og 26 prosent hadde vore til kontroll i spesialisthelsetenesta det siste året.»}


Berre 44 prosent hadde vore til fastlegekontroll, og 26 prosent hadde vore til kontroll i spesialisthelsetenesta det siste året. 40 prosent hadde fått tilbod om LMSkurs (86 prosent av desse gjennomførte), og 19 prosent hadde fått tilbod om rehabilitering (95 prosent gjennomførte). Om lag halvparten hadde middels eller høg grad av aktivering for eigenomsorg målt med PAM 13 (20).

\section{Utfordringar i kvardagen}

I delstudie II gjorde vi individuelle kvalitative intervju med seks menn og fem kvinner i alderen 62-76 år. Alle budde heime og fekk ikkje hjelp til dagleg eigenomsorg, og tre budde åleine. I intervjua kom det fram at kvardagen gav dei store utfordringar med å lære seg sjølv og sjukdommen å kjenne, og dei brukte mykje tid og krefter på å trene og meistre daglege utfordringar.

\section{三 «For å klare kvardagen hadde dei god nytte av rehabilitering og opplæring, om dei fekk det.»}

For å klare kvardagen hadde dei god nytte av rehabilitering og opplæring, om dei fekk det, men dei hadde framleis kontinuerleg behov for trygg tilgang til kompetent hjelp. Det kom òg fram at dei ikkje trudde fastlegane hadde god nok kompetanse. Dei kjende seg meir trygge på spesialisthelsetenesta, men ved akutte innleggingar vart dei utrygge av å møte stadig nytt helsepersonell som ikkje kjende problema deira (22).

\section{Tilrådingar ikkje følgde}

Ifølgje brukarrapporterte data frå dette utvalet er tilrådingane om oppfølging i stabil fase (10) ikkje følgde. Data syner òg at eigenomsorgsaktiveringa burde vore høgre, og at brukarane i høg grad har nytta seg av dei tilboda dei har fått om opplæring og støtte. 
Den kvalitative studien fortel om ein strevsam kvardag med behov for opplæring og rehabilitering for å meistre kvardag og forverringsepisodar, og behov for sikker tilgang til kvalifisert hjelp, spesielt når det oppstår akutte forverringar. Manglande tillit til fastlegane gjorde at dei som hadde kontaktar i spesialisthelsetenesta, føretrekte å ta kontakt med den når dei trong hjelp.

Desse studiane tyder på at sårbare område for denne brukargruppa er faktisk å få tilbod om opplæring og rehabilitering, jamlege kontrollar og rask tilgang til kvalifisert hjelp ved akutte kols-forverringar, noko som vanlegvis oppstår mange gonger i sjukdomstida. Unytta ressursar er den kunnskapen og viljen brukarane har til å gjennomføre god eigenomsorg dersom dei får nødvendig støtte til dette frå kompetent helsepersonell som dei har tillit til.

\section{Våre erfaringar}

Prosjektet har gitt oss nyttig erfaring med samarbeidsforsking på kols-feltet. Medforskarane var svært motiverte for å delta i arbeid som skulle gi innspel til betre tenester. Dei hadde tydelege prioriteringar for kva dei ønskte å undersøkje, og gav verdifulle bidrag til utforming av problemstillingar, informasjonsskriv og ad hoc-spørjeskjema, analysar, utforming av manus og innlegg på fagmøte.

Det var likevel svært krevjande for brukarane å delta på kurs og forsking, og delar av medforskarkurset låg på eit for avansert fagleg nivå. Denne tilbakemeldinga er viktig for å justere seinare kurs: Dei må nøye tilpassast føresetnadene til deltakarane. Medforskarane brukte mykje tid og krefter, og arbeidet tok lengre tid enn det som var planlagt.

\section{三 «Eit prosjekt med deltakarar som er alvorleg sjuke, må tole fråfall.»}


Brukarane stilte med eigne ressursar i form av erfaringskunnskap og motivasjon, men var samtidig sårbare. Ein brukar måtte ha pause undervegs på grunn av helseplager, og ein brukar døydde undervegs i prosjektet. Vi meiner difor at det er viktig å inkludere mange brukarar. Eit prosjekt med deltakarar som er alvorleg sjuke, må tole fråfall. Det er òg viktig å ha med mange medforskarar for å oppnå maktutjamning og likeverdige dialogar $(17,23)$.

Det er ei felles oppfatning i gruppa at god praktisk tilrettelegging, tid til diskusjonar og uformelt samvær, og vektlegging av samarbeidsklimaet har vore viktig for å oppnå likeverdig deltaking for alle partar. Ein annan viktig føresetnad har vore at det vart løyvd midlar til slikt samarbeid: ekstra tid, driftsutgifter og løn til medforskarane.

\section{Konklusjon}

Hovudkonklusjonane etter dette arbeidet er difor 1) at samarbeidsforsking er eit godt design for kvalitetsforbetring av oppfølgingstenester, og 2) at studiane viste at kols-retningslinene frå 2012 og samhandlingsreforma ikkje var tilstrekkeleg implementerte i dei undersøkte utvala.

\section{Referansar}

1. Forskningsrådet. Brukermedvirkning i helseforskningsprogrammene. 2017. Tilgjengeleg frå: https://www.forskningsradet.no/prognett-globvac/Artik kel/Brukermedvirkning_i_helseforskningsprogrammen e/1254019674478?langno (lasta ned 11.12.2017).

2. Helse Vest. Nasjonalt program for klinisk behandlingsforskning. 2018. Tilgjengeleg frå: http://kli niskforskning.rhf-forsk.org/brukermedvirkning/ (lasta ned 20.01.2018). 
3. Moltu C, Stefansen J, Svisdal M, Veseth M.

Negotiating the co-researcher mandate-service users' experiences of doing collaborative research on mental health. Disability and Rehabilitation.

2012;34(19):1608-16.

4. Halding AG, Fossøy AB, Moltu C, Grov EK. «Eit givande, men krevjande lagspel for å betre tenestene». Brukarerfaringar frå samarbeidsforsking. Nordisk tidsskrift for helseforskning. 2016;12(1):3448.

5. Borg M, Kristiansen K, Glover H, Volden O, Beston G, Hauge S, et al. Medforskning: å forske sammen for kunnskap om psykisk helse. Oslo: Universitetsforlaget; 2009.

6. Johannessen A, Natland S, Støkken AM. Samarbeidsforskning i praksis: erfaringer fra HUSKprosjektet. Oslo: Universitetsforlaget; 2011.

7. GOLD. Global strategy for the diagnoses, management and prevention of chronic obstructive pulmonary disease. 2017. Tilgjengeleg frå: file:///C:/U sers/sigfla/Downloads/wms-GOLD-2017FINAL.pdf (lasta ned 10.12.2017).

8. Bratås O. Multidiciplinary rehabilitation in patients with Chronic Obstructive Pulmonary Disease (COPD) - incentives for choosing rehabilitation and short- and long-term effects. (Doktoravhandling). Trondheim: Norges teknisk-naturvitenskapelige universitet, Fakultet for samfunnsvitenskap og teknologiledelse, Institutt for sosialt arbeid og helsevitenskap; 2011.

9. Halding A, Heggdal K. Patients' experiences of health transitions in pulmonary rehabilitation. Nursing Inquiry. 2012;19(4):345-56. 
10. Helsedirektoratet. Kols. Nasjonal faglig retningslinje og veileder for forebygging, diagnostisering og oppfølging. Oslo: Helsedirektoratet; 2012. Tilgjengeleg frå: https://helsedirektoratet.no/retn ingslinjer/nasjonal-faglig-retningslinje-og-veileder-forforebygging-diagnostisering-og-oppfolging-av-persone r-med-kols (lasta ned 10.12.2017).

11. St.meld. nr. 47 (2008-2009).

Samhandlingsreformen.Oslo: Helse- og omsorgsdepartementet; 2009. Tilgjengeleg frå: https:// www.regjeringen.no/no/dokumenter/stmeld-nr-47-200 8-2009-/id567201/ (lasta ned 10.12.2017).

12. Bourbeau J. The role of collaborative selfmanagement in pulmonary rehabilitation. Seminars in Respiratory \& Critical Care Medicine. 2009;30(6):700-7.

13. Zwerink M, Brusse-Keizer M, van der Valk PDLPM, Zielhuis GA, Monninkhof EM, van der Palen $\mathrm{J}$, et al. Self-management for patients with chronic obstructive pulmonary disease. Cochrane Database Syst Rev. 2014; 19(3):CD002990.

14. Oliver S, Liabo K, Stewart R, Rees R. Public Involvement in research: making sense of diversity. Journal of Health Services \& Policy. 2015;20(1):4551.

15. Domecq J, Prutsky G, Elraiyah T, Wang Z, Nabhan M, Shippee N, et al. Patient engagement in research: a systematic review. BMC Health Services Research. 2014;14:89. DOI: 10.1186/1472-6963-1489.

16. Svisdal M, Moltu C, Sletvold E. Forskerskole for medforskere: evalueringsrapport. Stavanger: Helse Vest, Det regionale samarbeidsorganet, Regionalt forskningsnettverk for stemningslidelser; 2010. 
17. Larsen T, Sagvaag H. Brukermedvirkning: mer enn fordeling av makt i tjenesteutvikling. I:

Johannessen A, Natland S, Støkken AM, red.

Samarbeidsforskning i praksis. Oslo:

Universitetsforlaget; 2011. s. 52-67.

18. COPD Assessment test [internett]. Middlesex:

COPD; 2016 [oppdatert 10.2016, sitert 14.10.2016].

Tilgjengeleg frå: http://www.catestonline.org/.

19. Insignia Health. The Patient Activation

Measure ${ }^{\circledR}\left(\mathrm{PAM}{ }^{\circledR}\right)$ 2018. Tilgjengeleg frå: https://ww w.insigniahealth.com/products/pam-survey (lasta ned 14.10.2016).

20. Bondevik M. The life of the oldest old: studies concerning loneliness, social contacts, activities of daily living, purpose in life and religiousness.

(Doktoravhandling.) Universitetet i Bergen; 1997.

21. Halding A, Grov E. Self-rated health aspects among persons living with chronic obstructive pulmonary disease. International Journal of Chronic Obstructive Pulmonary Disease. 2017;12:1163-72.

22. Halding AG, Aarsheim EI, Jensen AJ, Stavøstrand S, Grov E. Chronic Obstructive Pulmonary Disease transitions in health and selfmanagement: service users' experiences from everyday life. International Journal of Chronic Obstructive Pulmonary Disease. 2018;13:2075-88.

23. Pauravaara K. Reflections on collaborative research: to what extent and on whose terms? Scandinavian Journal of Disability Research. 2015;17(3):272-83. 